\title{
FUNÇÃO SOCIAL DAS EMPRESAS NAS RELAÇÕES DE TRABALHO E O TRABALHO DECENTE
}

\author{
SOCIAL FUNCTION OF ENTERPRISES IN WORK RELATIONS AND DECENT WORK
}

\section{Antônio Leonardo Amorim}

\begin{abstract}
Mestre em Direito pela Universidade Federal de Mato Grosso do Sul, professor no curso de Direito da Universidade Federal de Jataí (UFJ) e na Universidade Estadual do Mato Grosso (UNEMAT).

E-mail: tomy_ocara@hotmail.com
\end{abstract}

\section{Ynes da Silva Félix}

\begin{abstract}
Professora titular da Universidade Federal de Mato Grosso do Sul e Diretora da Faculdade de Direito da UFMS, professora permanente do curso de mestrado em Direito da Faculdade de Direito da Universidade Federal de Mato Grosso do Sul, Doutora em Direito pela Pontifícia Universidade Católica de São Paulo.

E-mail: ynesil@uol.com.br
\end{abstract}

Recebido em: 31/05/2019

Aprovado em: 17/10/2019

RESUMO: Função social é um tema abordado de forma exaustiva em diversas áreas do direito, porém, sempre apresentado com divergência, seja em seu caráter conceitual como em seu aspecto normativo e integrativo. A doutrina não tem apresentado um conceito claro e explicativo sobre a função social da empresa, e isso se dá em razão do poder econômico que essa tem, além de suas atribuições originariamente impositivas. Sabe-se que as empresas tem poder econômico em detrimento do trabalho, porém, na perspectiva da proteção do valor social do trabalho humano prevista constitucionalmente, a função social da empresa deve ser vista a partir desse paradigma de ditame da justiça social. Nessa perspectiva, esse trabalho se encarrega de demonstrar a necessidade da ocorrência da função social das empresas nas relações de trabalho, bem como da incidência do trabalho decente, esse último com dericavo no conceito do plano de desenvolvimento da Organização Internacional do Trabalho, que objetiva garantir a todos os trabalhadores brasileiros melhores condições de trabalho, bem como a sua realização de forma livre e adequadamente remunerado. Assim, será demonstrado nesse trabalho científico que as empresas tenham função social nas relações de trabalho, em especial, obedecendo os ditames do trabalho decente.

Palavras-chave: Função Social, Empresas, Relações, Trabalho, Trabalho Decente.

ABSTRACT: Social function is an exhaustively addressed topic in several areas of law, but always presented with divergence, both in its conceptual character and in its normative and integrative aspect. The doctrine has not presented a clear and explanatory concept about the social function of the company, and this is due to the economic power it has, in addition to its originally imposed duties. It is known that companies have economic power over work, but in view of protecting the social value of human labor constitutionally foreseen, the social function of the company must be seen from this paradigm of social justice. In this perspective, this work is responsible for demonstrating the need for the social function of enterprises in labor relations, as well as the incidence of decent work, the latter with the concept of the development plan of the International Labor Organization, which aims to guarantee to all Brazilian workers better working conditions, 
as well as their realization in a free and adequately remunerated way. Thus, it will be demonstrated in this scientific work that companies have a social function in labor relations, especially, obeying the dictates of decent work.

Keywords: Social Work, Business, Relationships, Work, Decent Work

SUMÁRIO: Introdução; 1 Relação de Trabalho e Emprego; 2 Função Social da Propriedade Privada e seus Aspectos; 3 A Função Social das Empresas nas Relações de Trabalho; 4 Trabalho Decente; Considerações Finais; Referências Bibliográficas;

SUMMARY: Introduction; 1 Relation of Work and Employment; 2 Social Function of Private Property and its Aspects; 3 The Social Function of Companies in Labor Relations; 4 Decent Work; Final Considerations; Bibliographic References;

\section{INTRODUÇÃO}

Este trabalho traz a discussão sobre a necessidade que a empresa cumpra sua função social nas relações de emprego em conformidade com os preceitos constitucionais e alinhado ao conceito de trabalho decente da Organização Internacional do Trabalho, inserido no Brasil pelo Plano Nacional do Trabalho Decente.

A propriedade privada constitucionalmente deve cumprir seu papel social, no mesmo sentido, a doutrina aponta que as empresas, por serem consideradas analogicamente propriedade privada, devem dar cumprimento aos preceitos da função social determinada pelo constituinte originário.

Nesse diapasão, surge então indagações a serem feitas sobre o que seria essa função social da empresa, como se daria o seu cumprimento nas relações de trabalho e o dever de obedecer ao preceito de trabalho decente exposto pela OIT, que inclusive tem sido reafirmado na meta 8.3 dos Objetivos de Desenvolvimento Sustentável da ONU, que o Brasil se comprometeu em cumprir até 2030 .

A função social da empresa tem resguardo constitucional e em leis ordinárias, porém, seu conceito não está devidamente claro e demonstrado, estando apenas afirmado constitucionalmente que a função social da empresa deve ser fundada na valorização do trabalho, por isso, a correlação desse tema.

Assim, surge então o seguinte problema de pesquisa, as empresas devem ter função social nas relações de trabalho alinhavada ao conceito de trabalho decente? Essa indagação será respondida com base na doutrina, na lei, utilizando-se do método hipotético dedutivo e da pesquisa bibliográfica.

O objetivo geral deste trabalho é demonstrar a função social da empresa nas relações de trabalho, e como objetivos específicos, descrever essa função social alinhada à Constituição Federal de 1988, constatar a efetividade da função social das empresas nas relações de trabalho e demonstrar a necessidade de existência de função social nas relações de trabalhos alinhado ao conceito de trabalho decente.

\section{RELAÇÃO DE TRABALHO E EMPREGO}

Faz-se mister, apresentar existentes entre relação de trabalho e relação de emprego, com o objetivo de demonstrar que existe diferença significativa entre subordinação e subordinação jurídica, as quais tem estrita correlação com a relação de trabalho e relação de emprego.

Vale frisar que a expressão relação de trabalho é ampla e genérica, englobando qualquer 
atividade que se exerça a partir da força laborativa do ser humano, por ser amplo, englobaria a expressão relação de emprego (DELGADO, 2017, p. 310). Muito embora a expressão relação de trabalho tenha essa amplitude, deve ser vista como meio de regulamentação das relações da prestação de força de trabalho humano.

Nas relações de trabalho temos, por exemplo, a ocorrência de trabalho autônomo, trabalho eventual, trabalho avulso, assim, compreende qualquer relação de trabalho a ser exercida, porém, deve-se observar assim como na relação de emprego a sua modalidade de vinculação jurídica, que por via de regra necessitam de duas partes para sua ocorrência, como contratante e contratado, empregado e empregador (BARROS, 2016, p. 144).

Relação de trabalho está intimamente ligada ao contrato de trabalho, por isso, na visão contratualista é necessário que seja vista como elemento caracterizador do macro, o que difere, por exemplo, da caracterização da relação de emprego que por razões preferenciais do legislador se viu na necessidade de regula-la (NASCIMENTO, 2012, p. 547).

Diante disso, considerando que relação de trabalho é gênero e relação de emprego é espécie, Maurício Godinho Delgado (2017, p. 313) apresenta os elementos que entende necessário para caracterizar a relação de emprego afirma:

De fato, a relação empregatícia, enquanto fenômeno sociojurídico, resulta da síntese de um diversificado conjunto de fatores (ou elementos) reunidos em um dado contexto social ou interpessoal. Desse modo, o fenômeno sociojurídico da relação de emprego deriva da conjugação de certos elementos inarredáveis (elementos fático-jurídicos), sem os quais não se configura a mencionada relação. Os elementos fático-jurídicos componentes da relação de emprego são cinco: a) prestação de trabalho por pessoa física a um tomador qualquer; b) prestação efetuada com pessoalidade pelo trabalhador; c) também efetuada com não eventualidade; d) efetuada ainda sob subordinação ao tomador dos serviços; e) prestação de trabalho efetuada com onerosidade.

A caracterização da relação de emprego dependerá dos elementos necessários para a caracterização propriamente do vínculo empregatício, o qual é explicado pela análise do art. $2^{\circ} \mathrm{e}$ art. $3^{\circ}$, da CLT, esse último, ao conceituar o empregado afirma que é "toda pessoa física que presta serviços de natureza não eventual a empregador, sob a dependência deste e mediante salário" (BRASIL, 1943).

Essa caracterização dependerá da análise concreta da forma como ocorre a relação de emprego, assim, Georgenor de Sousa Franco Filho (2015, p. 167) traz cinco elementos para a caracterização da relação de emprego, e, por conseguinte suficientes a ensejar o reconhecimento de vínculo empregatício "1. Ser pessoa física; 2. Prestar serviços não eventuais; 3. Existir um tomador do serviço; 4. Receber ordens e instruções; 5. Receber salário pelos serviços" (FRANCO FILHO, 2015, p. 167).

Dos elementos demonstrados pela Consolidação das Leis do Trabalho e pelas doutrinas trazidas, tem-se que a subordinação jurídica é o elemento mais importante desta relação, e deve ser visto no aspecto contratualista, que nos informa o dever das partes contratantes no cumprimento dos deveres expressados na relação.

A subordinação jurídica pode ser conceituada como "o polo reflexo e combinado do poder de direção empresarial, também de matriz jurídica. Ambos resultam da natureza da relação de emprego, da qualidade que lhe é ínsita e distintiva" (DELGADO, 2017, p. 327).

Nesse ínterim, DELGADO (2017, p. 328-329) propõe três dimensões da subordinação como sendo a clássica, objetiva e estrutural:

Clássica (ou tradicional) é a subordinação consistente na situação jurídica derivada do contrato de trabalho, pela qual o trabalhador compromete-se a acolher o poder de direção empresarial no tocante ao modo de realização de sua prestação 


\begin{abstract}
laborativa.
(...)

Objetiva é a subordinação que se manifesta pela integração do trabalhador nos fins e objetivos do empreendimento do tomador de serviços ainda que afrouxadas. (...)

Estrutural é, finalmente, a subordinação que se expressa pela inserção do trabalhador na dinâmica do tomador de seus serviços, independentemente de receber ou não suas ordens diretas.
\end{abstract}

E, arremata fazendo uma conjugação dessas três dimensões da subordinação (DELGADO, p. 329) "que não se excluem, evidentemente, mas se completam com harmonia - permite se superarem as recorrentes dificuldades de enquadramento dos fatos novos do mundo do trabalho ao tipo jurídico da relação de emprego".

Essa conjugação se faz necessária para os fins de enquadramento e melhor interpretação a ser dada para o conceito de subordinação jurídica, que como bem expressado, pode ser considerado como meio de integração, inserção e subordinação propriamente dita do empregado na relação de emprego.

De outro norte, sobre a figura do empregador, o seu conceito está descrito no art. $2^{\circ 1}$, da CLT, o qual dispõe que empregador é aquele que assume os riscos do negócio, da atividade exercida, assalaria seus empregados, dirige a forma de realização do trabalho nas dependências da empresa.

SUSSEKIND (2005, p. 291) ao conceituar o empresário com base no Código Civil afirma que "é quem exerce profissionalmente atividade econômica organizada para a produção ou a circulação de bens ou de serviços (art. 966)", assim, como principal forma de caracterização da figura do empregador pode-se apontar a atividade econômica e organizada por ele garantida e efetivada, bem como a condução dessa atividade.

Não apenas só essa figura de empregador/empresário que se busca trazer para fins de consideração, mas sim aquele que se organiza de forma suficiente a promover normas de direitos humanos, como é o caso do trabalho decente, e, não apenas o que busca auferir lucro com a prestação dos serviços.

Ao apresentar o conceito de empresário moderno, Fábio Ulhoa Coelho (2017, p. 30) afirma que é aquele que com "noções de profissionalismo, exerce atividade econômica organizada e produção ou circulação de bens ou serviços". Com isso, tem-se que a empresa se compõe de um conceito voltado para a economia, no entanto, deve buscar também, a promoção de normas de direitos humanos, como complemento da sua existência em uma sociedade civil organizada.

\title{
2 FUNÇÃO SOCIAL DA PROPRIEDADE PRIVADA E SEUS ASPECTOS
}

A propriedade deve atender a função social, sob pena de não ser protegida como dispõe a Constituição Federal de 1988. Antes disso, é necessário saber qual o conceito e o que é função social da propriedade, justamente porque a doutrina não é clara suficiente para atribuir um conceito preciso.

Função social tem a ver com conjunto ou mecanismos de proteção de direitos do que realmente é de interesse da sociedade (AURÉLIO, 2018²), e isso se justifica a necessidade de conceituá-la, justamente para que possamos discorrer sobre a função social das empresas.

A função social da propriedade historicamente tem se iniciado na Constituição de 1934, e, apenas surge claramente o seu conceito na Constituição Federal de 1988, que em seu art. 170,

\footnotetext{
${ }^{1}$ Art. $2^{\circ}$. Considera-se empregador a empresa, individual ou coletiva, que, assumindo os riscos da atividade econômica, admite, assalaria e dirige prestação pessoal de serviços. (...)

${ }^{2}$ Disponível em: < https://dicionariodoaurelio.com/social $>$. Acesso em 10 de mai. 2018.
}

Revista de Direito Brasileira | Florianópolis, SC | v. 24 | n. 9 | p.183-196 | Set./Dez. 2019 
traz a seguinte previsão:

Art. 170. A ordem econômica, fundada na valorização do trabalho humano e na livre iniciativa, tem por fim assegurar a todos existência digna, conforme os ditames da justiça social, observados os seguintes princípios: I - soberania nacional; II - propriedade privada; III - função social da propriedade; IV - livre concorrência; V - defesa do consumidor; VI - defesa do meio ambiente, inclusive mediante tratamento diferenciado conforme o impacto ambiental dos produtos e serviços e de seus processos de elaboração e prestação; VII - redução das desigualdades regionais e sociais; VIII - busca do pleno emprego; IX - tratamento favorecido para as empresas de pequeno porte constituídas sob as leis brasileiras e que tenham sua sede e administração no País. Parágrafo único. É assegurado a todos o livre exercício de qualquer atividade econômica, independentemente de autorização de órgãos públicos, salvo nos casos previstos em lei. (grifos acrescidos).

O art. 170, da CF, vai muito além da simples previsão da função social da propriedade, afirma que a ordem econômica do Brasil será pautada na valorização do trabalho humano, na livre iniciativa, com o único objetivo de assegurar a todos brasileiros existência humana com dignidade, e traz os princípios que entende necessário para essa concretização, o qual destacamos para abordar, a função social da propriedade.

Alexandre de Moraes (2017, p. 599) ressalta que "o artigo 170 estabeleceu a finalidade à ordem constitucional: garantia de existência digna, conforme os ditames da justiça social”, como bem demonstrado, o que é a única forma de efetivação dos ditames da justiça social apresentado no caput do artigo mencionado.

No mesmo sentido, Ingo Wolfgang Sarlet, Luiz Guilherme Marinoni e Daniel Mitidiero (2017, p. 637), trazem as seguintes disposições:

(...) o art. 170, que explicita a valorização do trabalho humano e a livre iniciativa como fundamentos da ordem econômica, vinculando esta última à garantia de uma existência digna para todos, conformada aos ditames da justiça social, de tal sorte que se pode afirmar que a dignidade da pessoa humana é também o fundamento e o fim da ordem econômica na Constituição.

Bem é verdade que a valorização do trabalho humano é pressuposto necessário para a concretização da dignidade da pessoa humana, como demonstrado pelos doutrinadores acima mencionado, com isso, deve-se promover por todos os meios a concretização desses valores sociais, com vistas a garantir a plena efetividade da justiça social determinada pelo art. 170, da CF.

Com o objetivo de tratar com unidade os princípios acima expostos, Ana Frazão de Azevedo (2006, p. 278) a partir de uma análise do capitalismo e da sua integração na Constituição Federal afirma que:

O Estado democrático de direito traz em si uma unidade de sentido que permeia toda a Constituição e orienta a compreensão dos demais princípios: a dignidade da pessoa humana, como conceito que consagra simultaneamente a autonomia privada e a autonomia pública. Logo, muito mais importante do que discutir qual é o grau de capitalismo adotado pela Constituição é saber que a ordem econômica tem por fim assegurar a todos uma existência digna, conforme os ditames da justiça social, tal como acentua o próprio caput do art. 170.

O mais importante é a proteção do Estado democrático de direito, o qual em sua completude tem como objetivo a compreensão e efetivação dos princípios inerentes à proteção da dignidade da pessoa humana, com o único fim, assegurar a todos os seres humanos a sua existência 
com dignidade (AZEVEDO, 2006, p. 278).

Com isso, o primado do princípio que afirma que a propriedade deve ter função social deve ser interpretado à luz da valorização do trabalho humano, devendo-se buscar sempre a efetivação dos direitos inerentes a todos os cidadãos, direitos esses básicos e necessários para se chegar o que pretende o plano nacional do trabalho decente.

Sobre a importância do princípio da função social, sua importância, incidência no direito comparado, Gilmar Mendes (2009, p. 1.407) traz um contexto histórico e representativo, nos seguintes termos:

Para se ter ideia da importância que esse princípio assumiu no mundo contemporâneo, basta se ter presente o que diz o art. 14-2 da Constituição da Alemanha — "a propriedade obriga" —, um configura, sem sombra de dúvida, a mais radical contraposição ao dogma individualista que reputava sagrado o direito de propriedade e assegurava ao seu titular, em termos absolutos, o poder de usar, gozar e dispor dos seus bens - jus utendi, fruendi et abutendi -,sem nenhuma preocupação de caráter social. Não por acaso, foi a Constituição de Weimar a primeira a conter um bloco normativo especificamente destinado a regular a atividade econômica, no que veio a ser imitada por diversas cartas políticas que se lhe seguiram, como a nossa Constituição de 1934- Pois bem, em breve anotação a mencionado att. 14-2 da Lei Fundamental de Bonn, ressalta Nuno Rogeiro que, por meio desse dispositivo, a União Democrata Cristã (CDU) e o Partido Social Democrata (SPD) - os principais partidos políticos alemães —, "em função da doutrina social da Igreja e de uma visão 'marxista democrática', depois esbatida e até abandonada, estatuíram o credo comum do valor social da propriedade", um standard axiológico tão relevante que passou a integtar o texto das principais constituições do nosso tempo. No Brasil, esse princípio adquiriu cidadania constitucional com a já referida Carta Política de 1934, cujo art. 113, item 17, na linha da nossa tradição jurídica, continuou a assegurar o direito de propriedade, com a ressalva - e nisso consistiu a novidade — de que, doravante, ele não poderia ser exercido contra o interesse social ou coletivo.

Ainda complementa o autor (MENDES, 2009, p. 1.408):

Sendo a função social da propriedade, como sabemos, um princípio jurídico e não uma regra de direito, a sua implementação insere-se no jogo concertado de complementações e restrições recíprocas em que consiste o processo de aplicação/concretização dessas pautas axiológicas - por natureza abertas, indeterminadas e plurissignificativas - enquanto mandatos de otimização. Essa qualificação, por conseguinte, remete-nos à ideia de que a função social da propriedade é um tipo de norma que não se implementa em termos absolutos e excludentes de outras — antes opera gradualmente e dentro do possível - a depender tanto de condições fáticas, que são impostas pela realidade extranormativa, quanto de condições jurídicas, a serem determinadas pelos princípios e regras contrapostos.

O posicionamento defendido por Gilmar Mendes (2009) não está em consonância com o que dispõe o texto constitucional, justamente pelo fato de que o texto afirma que deverá em prol do cumprimento da ordem econômica o Brasil promover, com o fim de assegurar valorização do trabalho, a função social da propriedade.

Nessa vereda, a interpretação a ser dada ao princípio da função social da propriedade deve estar alinhavada aos ditames da ordem econômica, do valor social do trabalho, da livre iniciativa, com o único objetivo, o alcance da justiça social e, não depender de condições fáticas como pretende Gilmar Mendes (2009). 
De outro norte, Fábio Konder Comparato (2008, p. 132), analisa o conceito de função social exposto na Constituição Federal de 1988 como extensão à função que a empresa deve cumprir:

No Brasil, a ideia da função social da empresa também deriva da previsão constitucional sobre a função social da propriedade (art. 170, inciso III). Estendida à empresa, a ideia de função social da empresa é talvez uma das noções de mais relevante influência prática e legislativa no direito brasileiro. É o principal princípio norteador da "regulamentação externa" dos interesses envolvidos pela grande empresa. Sua influência pode ser sentida em campos tão díspares como direito antitruste, direito do consumidor e direito ambiental.

Justamente é essa correlação que se pretende fazer nesse trabalho, da vinculação da função social da empresa à função social da propriedade privada, buscando em ambas a observância da premissa maior, que é a justiça social, em especial para atender o problema de pesquisa deste artigo que é o da valorização do trabalho.

No mesmo sentido, com o objetivo de correlacionar o princípio da função social da propriedade com a função social da empresa Zulmar Fachin (2013, p. 586) firma seu posicionamento afirmando que "esse princípio exige que a propriedade privada atenda não apenas aos interesses do proprietário, mas também aos da coletividade. Nesse sentido, fala-se também em função social da empresa".

Com isso, se faz necessário descrever o que é a função social da empresa, além de demonstrar como vem sendo abordado pela doutrina e as discussões existentes e sua correlação com o trabalhador e o trabalho decente.

\section{A FUNÇÃO SOCIAL DAS EMPRESAS NAS RELAÇÕES DE TRABALHO}

A função social da empresa deve estar alinhada ao meio de valorização do trabalho humano com o objetivo de alcançar a justiça social, como determina o art. 170, da Constituição Federal.

Por isso, a terminologia função social no que se refere às atividades das empresas tem incidência em diversas legislações, como por exemplo, nos artigos 116 , parágrafo único ${ }^{3}$ e $154^{4}$ da Lei n. 6.404/1976, art. $47^{5}$, da Lei n. ${ }^{\circ} 11.101 / 2005$ e no art. $421^{6}$, do Código Civil, normas essas de incidência direta nas atividades das empresas.

Muito embora a doutrina não seja equânime no conceito do que é função social da empresa, o professor Fábio Ulhoa Coelho (2012, p. 81) apresenta o conceito mais completo da função social da empresa:

Cumpre sua função social a empresa que gera empregos, tributos e riqueza, contribui para o desenvolvimento econômico, social e cultural da comunidade em que atua, de sua região ou do país, adota práticas empresariais sustentáveis visando à proteção do meio ambiente e ao respeito aos direitos dos consumidores. Se sua atuação é consentânea com estes objetivos, e se desenvolve com estrita

\footnotetext{
${ }^{3}$ Art. 116. (...) Parágrafo único. $\mathrm{O}$ acionista controlador deve usar o poder com o fim de fazer a companhia realizar o seu objetivo e cumprir sua função social, e tem deveres e responsabilidades com os demais acionistas da empresa, os que nela trabalham e para com a comunidade em que atua, cujos direitos e interesses deve lealmente respeitar e atender. ${ }^{4}$ Art. 154. O administrador deve exercer as atribuições que a lei e o estatuto lhe conferem para lograr os fins e no interesse da companhia, satisfeitas as exigências do bem público e da função social da empresa. (...).

${ }^{5}$ Art. 47. A recuperação judicial tem por objetivo viabilizar a superação da situação de crise econômico-financeira do devedor, a fim de permitir a manutenção da fonte produtora, do emprego dos trabalhadores e dos interesses dos credores, promovendo, assim, a preservação da empresa, sua função social e o estímulo à atividade econômica. (...).

${ }^{6}$ Art. 421. A liberdade de contratar será exercida em razão e nos limites da função social do contrato.
} 
obediência às leis a que se encontra sujeita, a empresa está cumprindo sua função social; isto é, os bens de produção reunidos pelo empresário na organização do estabelecimento empresarial estão tendo o emprego determinado pela Constituição Federal.

Nessa perspectiva, empresa será aquela que contribui para o desenvolvimento econômico e social da comunidade, muito embora o autor não traga as relações trabalhistas como pressuposto da função social da empresa, em uma interpretação integrativa a partir da contribuição social por ele apresentada, depreende-se a promoção dos direitos trabalhistas.

A promoção da função social da empresa nas relações de trabalho tem estrita correlação com o que aqui está sendo discutido, pelo fato de que nas relações de trabalho estão intimamente ligadas as relações econômicas, sociais e culturais, devendo ser protegidas e promovidas.

Por isso, as propriedades empresariais representadas pelas empresas devem atender à função social que dispôs o constituinte originário, quando no exercício da atividade econômica produza seus bens de forma a prevalecer a livre concorrência, bem com que não haja abuso de posição mercadológica (DINIZ, 2018).

Em um paralelo com as funções sociais da empresa em seus diversos aspectos, Alfredo Filho e José Luiz Bulhões Pedreira (2009, p. 837) afirmam que:

O acionista controlador tem o dever legal de fazer com que a companhia, além de realizar seu objeto (que é explorar atividade de produção e venda de bens e serviços com o fim de obter resultados e distribuí-los aos acionistas), cumpra sua função social (art. 116, par. único). A companhia, como toda sociedade empresária e todo empresário individual, exerce a função de criar, expandir e dirigir empresa e prover o capital de risco de que necessite, e a empresa é instituição fundamental na organização econômica e social das economias de mercado. A função precípua da empresa é produzir bens econômicos, mas devido às suas características, desempenha funções tanto na produção quanto na circulação econômica e na repartição de renda, e de agente da poupança e do investimento. O princípio de que os direitos subjetivos com que a ordem jurídica organiza a economia social devem ser exercidos de modo compatível com a função social que desempenham seus titulares, ou com os institutos jurídicos, difundiu-se modernamente e entre nós, informam o preceito constitucional sobre função social da propriedade diversas leis, como a LSA, e, mais recentemente, o preceito do Código Civil de que "a liberdade de contratar será exercida em razão e nos limites da função social do contrato" (art. 421 ). Os direitos patrimoniais e a proteção jurídica das diversas modalidades de poder são instrumentos da organização social assegurados aos agentes para que possam desempenhar com eficiência seus papéis sociais, e não privilégios ou prerrogativas instituídos em beneficio dos sujeitos ativos; o exercício desses direitos e poderes somente é legítimo, portanto, enquanto ajustado à função social que os explica e justifica.

Como observado a função social da empresa se forma desde a forma como o acionista nela está vinculado, para que então seja possível a ocorrência da economia social, para que então sejam garantidos aos trabalhadores a valorização do seu trabalho.

A incidência da função social da empresa vai além, não apenas nos atos do qual a empresa exerce, mas também até a retirada dos sócios, e isso se verifica nos ensinamentos de Fran Martins (2017, p. 401):

Art. 1.077: Nas hipóteses do art. 1.077 do Código Civil, cabe aos sócios delimitarem seus contornos para compatibilizá-los com os princípios da preservação e da função social da empresa, aplicando-se, supletiva (art. 1.053, parágrafo único) ou analogicamente (art. $4^{\circ}$ da LICC), o art. 137, § 
$3^{\circ}$, da Lei das Sociedades por Ações, para permitir a reconsideração da deliberação que autorizou a retirada do sócio dissidente.

Observa-se que a função social deve ser estritamente observada, desde o início das atividades da empresa até a retirada dos sócios, com o objetivo de primar pelo cumprimento da função social da empresa, o que se justifica em razão da criação desse meio de alcance da valorização do trabalho humano como bem expõe o art. $1^{\circ}, \mathrm{IV}^{7}$, e 170 , ambos da Constituição Federal de 1988.

O constituinte de 1988 elevou como um dos fundamentos do Estado Democrático de Direito o dever do Estado em dar integral cumprimento ao valor social do trabalho e da livre iniciativa e repete isso no art. 170, onde continua a afirmar que a no tocante a propriedade privada deve-se obedecer aos ditames da justiça social quanto na promoção da valorização do trabalho, com sua função social.

Fernando Boiteux em palestra proferida na Universidade de São Paulo, unidade de Ribeirão Preto/SP no evento "Função Social do Contrato", ocorrido no dia 19 de abril de $2018^{8}$, ao comentar sobre a função social e a livre iniciativa das empresas afirma que "quando se fala em liberdade de iniciativa, que você pode fazer o que quiser, a função social da empresa tem atributo público e isso pode se verificar em várias situações”.

Com o fim de correlacionar a função social da empresa nas relações de trabalho, Arnold Word (2012, p. 35) ao fazer um link entre a função social da empresa e outros ramos do direito como o direito do consumidor, concorrencial, bem como no direito do trabalho, afirma que:

A importância da empresa, entretanto, não está apenas na disciplina especificada pelo novo Código Civil e nas formalidades previstas para o regular exercício da atividade empresarial. Na sociedade contemporânea, a figura da empresa, em especial, da grande empresa, extrapola os interesses exclusivamente privados, uma vez que concilia interesses aparentemente divergentes de investidores, administradores, empregados, consumidores, do mercado e do Estado. Ressaltase que todos, em sua medida, são dignos de tutela pelo ordenamento jurídico. Assim, a disciplina da empresa está relacionada com os consumidores (direito do consumidor), com o bom funcionamento do mercado (direito concorrencial) e com os trabalhadores (direito do trabalho). Nesses ramos do direito, o conceito é formado com a interpretação das regras, pela doutrina e pela jurisprudência, tendo em vista o fim que se pretende atingir e os interesses a serem tutelados. Ademais, a própria Constituição Federal brasileira determina, em seu art. 170, que a ordem econômica tem por fim assegurar a todos existência digna, observando, entre outros, o princípio da função social da propriedade. De fato, a empresa representa um importante elemento na economia, que gera riquezas e está relacionada com o funcionamento do mercado e, em virtude disto, é relevante verificar a sua função social, isto é, o seu papel dentro da comunidade e a forma como está sendo usada. (...)

Assim, a empresa que desempenha uma função social traz alguns ditames para a conduta de quem é seu titular, relevando o seu perfil institucional e demonstrando que não tem apenas uma relevância para o direito comercial e privado, mas para outros ramos do direito, em especial, para o direito econômico e o direito do desenvolvimento.

A função social da empresa nas relações de trabalho deve necessariamente obedecer à existência da dignidade do trabalhador em suas atividades, muito embora diante da economia que

\footnotetext{
${ }^{7}$ Art. $1^{\circ}$. A república Federativa do Brasil, formada pela união indissolúvel dos Estados e Municípios e do Distrito Federal, constitui-se em Estado Democrático de Direito e tem como fundamentos: (...) IV - os valores sociais do trabalho e da livre iniciativa.

${ }^{8}$ Disponível em: <https://www.youtube.com/watch?v=YvUciE0f5hE $>$. Acesso em 10 de mai. 2018.
}

Revista de Direito Brasileira | Florianópolis, SC | v. 24 | n. 9 | p.183-196 | Set./Dez. 2019 
com sua pressão tenta inibir a ocorrência da função social da empresa nas relações de trabalho, não é essa a interpretação dada e integrada pelos mandamentos constitucionais já expostos.

Nas relações de trabalho a ocorrência da função social da empresa tende a ser um meio suficiente a dar cumprimento aos mandamentos do art. $1^{\circ}$, IV, e art. 170 , ambos da Constituição Federal, para que se alcance a existência da valorização do trabalho humano.

A função social da empresa está ligada no sentido de que essas devem cumprir com seu dever social de promover o trabalho nas condições livre e primando pela sua valorização e, não como meio de aniquilar a liberdade da empresa (LOPES, 2006, p. 81).

Ana Frazão de Azevedo Lopes (2006, p. 281) no tocante ao que entende da função social da empresa nas relações de trabalho afirma que "para efeitos da função social da empresa, o que verdadeiramente importa é a distribuição social dos benefícios econômicos, a fìm de proporcionar a todos uma existência digna".

Nesse sentido, a empresa só alcançará sua função social quando obedecer aos preceitos de valorização do trabalho humano bem como que cumpra com a necessidade de assegurar o cumprimento da justiça social.

Nesse sentido, Supiot (2014, p. 30), ao fazer comentários sobre a Declaração da Filadélfia, comenta sobre o que é o espírito da Filadélfia, afirmando que:

a) todos os seres humanos, qualquer que seja a sua raça, a sua crença ou o seu sexo, têm o direito de efetuar o seu progresso material e o seu desenvolvimento espiritual em liberdade e com dignidade, com segurança econômica e com oportunidades iguais; b) a realização das condições que permitem atingir este resultado deve constituir o objetivo central de qualquer política nacional e internacional; c) todos os programas de ação e medidas tomadas no plano nacional e internacional, nomeadamente no domínio econômico e financeiro, devem ser apreciados deste ponto de vista e aceites apenas na medida em que pareçam favorecer, e não prejudicar, o cumprimento deste objetivo fundamental.

No mesmo sentido, Fernando Boiteux (2018 $)$, afirma que “a função social da propriedade, do contrato e da sociedade, não depende apenas de norma jurídica, e também não pode ser completamente solucionada com a simples aplicação da lei”, para o professor, a função social da empresa deve cumprir com o que a sociedade espera dessa empresa quando do seu exercício.

Ainda, é importante consignar que a empresa que cumpre com a responsabilidade social, desempenha na sociedade uma função socioeconômica importante para que se efetive a paz social e solidariedade, o que, para Maria Helena Diniz (2018) é imperioso para o alcance da justiça social, uma vez que quando do cumprimento da responsabilidade social pelas empresas será garantido melhores condições sociais (DINIZ, 2018).

Desse modo, a empresa, em suas relações, seja ela estritamente privada ou pública, deve obedecer aos ditames da justiça social e aos preceitos estabelecidos pela própria função social intimamente esperada da empresa nas relações de trabalho, sob pena de violação direta do que se espera do papel da empresa e das suas relações.

\section{TRABALHO DECENTE}

Uma vez garantido constitucionalmente o dever de a empresa dar cumprimento a sua função social perante a sociedade, esta deve ainda cumprir com os preceitos de proteção do trabalho, em especial ao que dispõe sobre trabalho decente, como forma de valorização do trabalho humano.

\footnotetext{
${ }^{9}$ Disponível em: < https://www.youtube.com/watch?v=YvUciE0f5hE $>$. Acesso em 10 de mai. 2018.
} Revista de Direito Brasileira | Florianópolis, SC | v. 24 | n. 9 | p.183-196 | Set./Dez. 2019 
O resguardo do trabalho decente, e suas formas começaram a ser desenhada pela Organização Internacional do Trabalho em 1992, que por saber da necessidade de promover a igualdade de acesso ao trabalho produtivo das pessoas e na igualdade de oportunidades, deu início a um conceito com base na proteção social do trabalhador.

A conceituação do trabalho decente parte da OIT, porém, a doutrina tem contribuído de forma suficiente para exemplificar o conceito, nesse sentido Graça Druck (2011, p. 46) afirma que trabalho decente é "trabalho produtivo e adequadamente remunerado, exercido em condições de liberdade, equidade e segurança, sem quaisquer formas de discriminação, e capaz de garantir uma vida digna a todas as pessoas que vivem de seu trabalho".

Nota-se, que além do papel fundamental da empresa em cumprir com sua função social, deve essa obedecer ao que preceitua o conceito de trabalho decente, o qual afirma que o trabalho humano deve ser produtivo e remunerado em equidade, exercido de forma livre, com o único fim, qual seja, de promover ao trabalhador a valorização do seu trabalho, o que está em estrita consonância com o que preceitua o art. 1º, IV e art. 170, ambos da Constituição Federal de 1988.

Encontra-se também um conceito de trabalho decente no Plano Nacional do Trabalho Decente (Brasil, 2010, p.111), o qual é extraído do mandamento da Organização Internacional do Trabalho e inserido no plano interno como meio de promoção social:

Trabalho Decente é uma condição fundamental para a superação da pobreza, a redução das desigualdades sociais, a garantia da governabilidade democrática e o desenvolvimento sustentável. Em inúmeras publicações, o Trabalho Decente é definido como o trabalho adequadamente remunerado, exercido em condições de liberdade, equidade e segurança, capaz de garantir uma vida digna. Para a Organização Internacional do Trabalho (OIT), a noção de trabalho decente se apoia em quatro pilares estratégicos: a) respeito às normas internacionais do trabalho, em especial aos princípios e direitos fundamentais do trabalho (liberdade sindical e reconhecimento efetivo do direito de negociação coletiva; eliminação de todas as formas de trabalho forçado; abolição efetiva do trabalho infantil; eliminação de todas as formas de discriminação em matéria de emprego e ocupação); b) promoção do emprego de qualidade; c) extensão da proteção social; d) diálogo social.

A empresa ao cumprir com sua função social deve auxiliar os trabalhadores a superarem a pobreza, fazer com que sejam eliminadas as desigualdades sociais, além de garantir que nas relações de trabalho sejam obedecidos os preceitos fundamentais do direito do trabalho.

A Organização Internacional do Trabalho expôs o conceito de trabalho decente no ano de 2003, a qual apenas foi assinada pelo Brasil e inserida no plano interno em 2006, de igual modo, está previsto nos objetivos de desenvolvimento sustentável da ONU (2030) na meta 8.3 que será promovido o trabalho decente no Brasil.

Nota-se que o conceito de trabalho decente tem como objetivo trazer para o plano nacional o reconhecimento da liberdade, igualdade, segurança e equidade do emprego realizado de forma produtiva.

Extrai-se da agenda a prioridade em três segmentos (Brasil, 2010, p. 1): “a geração de melhores empregos com igualdade de oportunidades e de tratamento; a erradicação do trabalho escravo e eliminação do trabalho infantil, em especial em suas piores formas; e o fortalecimento dos atores tripartites e do diálogo social como um instrumento de governabilidade democrática".

Para que ocorra o trabalho decente é imperioso que esse seja adequadamente remunerado, e isso cabe à empresa quando do exercício de sua função social, nessa perspectiva, a doutrina de Tereza Cristina Gosdal (2006, p. 98) é suficientemente completa ao afirmar que o salario mínimo vigente no Brasil não é meio suficiente de dar cumprimento ao conceito de trabalho decente: 
É possível compreender-se que o salário mínimo, que constitui a remuneração de boa parte da população do país, garante as condições mínimas para uma vida saudável? Ou o conceito refere-se a um dever-ser abstrato, não à realidade concreta? E a possibilidade de pagamento do adicional de insalubridade em razão da existência de condições insalubres de trabalho? Não seria o caso de se proibir, então, qualquer trabalho em condições insalubres? Ou de se obrigar à melhoria das condições de trabalho, com a adoção de medidas de proteção coletiva dos trabalhadores, mesmo que tornando mais elevados os custos de produção?

Por isso, as empresas que buscam atender sua função social devem promover aos seus empregados condições de valorização do trabalho e de suas atividades, promovendo a esses a remuneração adequada como forma do alcance dos ditames da justiça social.

Nesse sentido, Tereza Cristina Gosdal (2006, p. 99) que "'a dignidade no trabalho é uma categoria axiológica aberta, que não pode ser fixada de modo definitivo, porque precisa ser permanentemente definida pelas situações concretas". Pois bem, o conceito de trabalho decente por vezes se alterará no tempo, em razão das mudanças sociais, e isso exige uma atualização constante desse conceito, sempre observando a vedação ao retrocesso.

Além disso, deve o trabalho decente pelo conceito trazido pela OIT assegurar o direito ao empregado da realização de trabalho em condições dignas, para que então possa ser chamado de trabalho decente.

Entende MOCELLIN (2009, p. 3) que "o negativo de trabalho decente seria trabalho precário". Desse modo, o conceito de trabalho decente é por via transversa o que não pode acontecer, pois caso isso ocorra, estaremos diante de violações às normas internacionais que o Brasil é signatário.

O negativo de trabalho decente, pode ser considerado o trabalho degradante ou em condições degradantes, o qual afronta esse memorando de entendimento assinado pelo Brasil, bem como a Declaração Universal de Direitos Humanos a qual somos signatários.

O trabalho degradante está intimamente ligado ao capitalismo que traz como seu corolário a obtenção de lucros e larga escala, pouco se importando com a condição do trabalho do ser humano.

O trabalho decente deve ser visto também como meio de implementação de um mínimo de norma a ser observada no direito do trabalho, e com isso temos o viés da dimensão moral do trabalho que na perspectiva de Fabrício Maciel (2006, p. 319) é a noção do que é bom e do que é mau para a vida do trabalhador, ao afirmar que "[...] um pano de fundo valorativo que estabelece os bens imateriais e as noções do que é bom e do que é mau, e, consequentemente, do que é uma boa vida que deve ser valorizada por todos, o que pode gerar distinções e hierarquias".

Desse modo, como demonstrado, as empresas devem cumprir seu papel social promovendo o trabalho decente, e garantindo aos trabalhadores a valorização do trabalho humano, como preceitua o art. $1^{\circ}$, IV, e art. 170, ambos da Constituição Federal, com o objetivo de que o trabalho seja realizado em condições adequadas suficientes a proporcionar ao ser humano a plena realização do emprego produtivo.

\section{CONSIDERAÇÕES FINAIS}

As empresas assim como a propriedade privada devem cumprir suas funções sociais estabelecidas constitucionalmente e em leis ordinárias, buscando sempre a efetividade da valorização do trabalho humano e da livre iniciativa, como preceitua os ditames constitucionais expostos nos artigos 1º, IV, e 170, ambos da Constituição Federal de 1988.

O compromisso das empresas em promoção da função social está intimamente ligado às relações de trabalho, justamente pelo fato de que a empresa não existe sem mão de obra, nessa perspectiva, a empresa deve promover sua função social no sentido de efetivar sua função social 
nessas relações.

Efetivar a função social da empresa nas relações de trabalho é meio suficiente de alcance da justiça social resguardada constitucionalmente e pela declaração de Filadélfia, objetivando a busca da paz social.

As empresas devem exercer suas atividades com o objetivo de obterem lucros em suas atividades, no entanto, esses lucros e suas atividades devem sempre observar a forma mais responsável possível de obtenção, justamente pelo fato de que constitucionalmente está resguardada a promoção da valorização do trabalho humano.

Do mesmo modo, promover o trabalho humano com valorização é o mesmo que resguardá-lo a partir do conceito de trabalho decente, que está intimamente ligado com essa valorização, bem como aos preceitos de garantir ao trabalhador condições mínimas de direitos sociais.

Nessa senda, a empresa deve promover sua função social com o objetivo de valorizar o trabalho humano de seus empregados alinhados ao preceito do trabalho decente os remunerando de forma adequada, resguardar os direitos fundamentais desses empregados, promover o diálogo social entre as instituições e, especialmente efetivar a justiça social, com o fim de proteção social dos empregados nas relações de trabalho.

\section{REFERÊNCIAS}

BRASIL. Constituição (1988).

BARROS. Alice Monteiro de. Curso de Direito do Trabalho. 10. ed. São Paulo: Ltr, 2016.

COELHO, Fábio Ulhoa. Curso de direito comercial, volume 1: direito de empresa. 21. ed. São Paulo: Saraiva, 2017.

COMPARATO, Fábio Konder. O poder de controle na sociedade anônima. Rio de Janeiro: Forense, 2008.

DELGADO. Mauricio Godinho. Curso de Direito do Trabalho. 16. ed. rev. e ampl. São Paulo: LTr, 2017.

DINIZ. Maria Helena. Importância Social da Empresa. Revista Unicuritiba. vol. 02, nº. 51, Curitiba, 2018. pp. 387-412.

DRUCK. Graça. Trabalho, Precarização e Resistências: Novos e Velhos Desafios. Disponível em: <http://www.ufjf.br/angelo_esther/files/2012/10/RH-I-PRECARIZA\%C3\%87\%C3\%80ODO-TRABALHO-2011.pdf >. Acesso em 10 de mar. 2018.

GOSDAL, T. C. Dignidade do trabalhador: um conceito construído sob o paradigma do trabalho decente e da honra. 2006. 195f. Tese (Doutorado em Direito) - Programa de PósGraduação em Direito, Universidade Federal do Paraná. Curitiba, 2006. Disponível em: <http://dspace.c3sl.ufpr.br/dspace/bitstream/handle/1884/4675/THEREZA\%20CRISTINA20GO SDAL.PDF;jsessionid=F7574BEF17D81611DD6688EE7671C2AC?sequence $>$. Acesso em 15 de mar. 2018.

FACHIN. Zulmar. Curso de Direito Constitucional. Rio de Janeiro: Forense, 2013.

FRANCO FILHO. Georgenor de Souza. Curso de Direito do Trabalho. LTR. 2015. 
LOPES, Ana Frazão de Azevedo. Empresa e Propriedade - função social e abuso de poder econômico. São Paulo: Quartier Latin, 2006.

MACIEL, Fabrício. Todo trabalho é digno?: um ensaio sobre moralidade e reconhecimento na modernidade periférica. In: SOUZA, J. (Org.) A invisibilidade da desigualdade brasileira. Belo Horizonte: UFMG, 2006.

MARTINS. Fran. Curso de Direito Comercial. 40. ed. rv., atual. e ampl. Rio de Janeiro: Forense, 2017.

MENDES, Gilmar Ferreira. Curso de direito constitucional. 4. ed. São Paulo: Saraiva, 2009.

MORAES. Alexandre de. Direito Constitucional. 33. ed. rev. e atual. São Paulo: Atlas, 2017.

MOCELIN, Daniel Gustavo. Do trabalho precário ao trabalho decente? A qualidade do emprego como perspectiva analítica. In: CONGRESSO DA ASSOCIAÇÃO DE ESTUDOS LATINO-AMERICANOS LASA, 28. Rio de Janeiro, 2009.

NASCIMENTO. Amauri Mascaro. Curso de Direito do Trabalho: História e teoria geral do direito do trabalho: relações individuais e coletivas do trabalho. 26. ed. São Paulo: 2011.

OIT - ORGANIZAÇÃO INTERNACIONAL DO TRABALHO. Agenda Nacional do Trabalho Decente. Brasília, 2006. Disponível em:

<http://www.oitbrasil.org.br/sites/default/files/topic/decent_work/doc/agenda_nacional_trabalho_ decente_536.pdf $>$. Acesso em: 12 mai. 2017.

SARLET. Ingo Wolfgang. MARINONI. Luiz Guilherme. MITIDIERO. Daniel. Curso de Direito Constitucional. São Paulo: Saraiva, 2017.

SUSSEKIND. Arnaldo Lopes. Instituições de direito do trabalho. São Paulo: LTr, 2005. 